Miguel Sicart

\title{
Game, Player, Ethics: A Virtue Ethics Approach to Computer Games
}

\section{Abstract:}

As the contemporary heirs of popular music or cinema, computer games are gradually taking over the markets of entertainment. Much like cinema and music, computer games are taking the spotlight in another front - that which blames them for encouraging unethical behaviors. Apparently, computer games turn their users into blood thirsty zombies with a computer game learnt ability of aiming with deadly precision.

The goal of this paper is to pay attention to the ethical nature of computer games, in order to understand better the ways we can evaluate their morality in western cultures providing a framework to understand some of these concerns. This paper poses questions about the ontology of games and their ethical meaning, in an attempt to give ethical theory a word in the analysis of computer games.

\section{Agenda}

Introduction 14

What games are 14

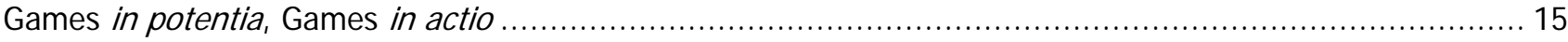

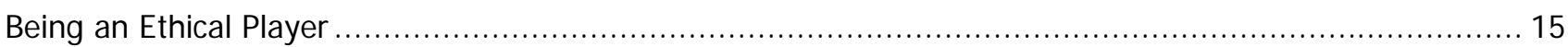

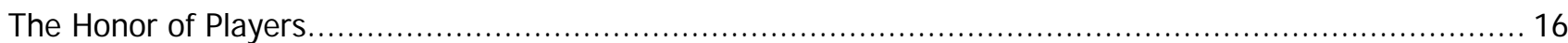

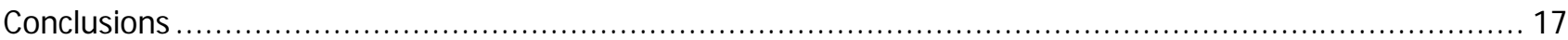

\section{Author:}

Miguel Sicart, Ph.D. Candidate:

- Organization and contact address:Center for Computer Game Research, IT University of Copenhagen, Ruedd Langgaards Vej 7, 2300 Copenhagen S, Denmark

- Telephone, email and personal homepage: $\widetilde{0} \mathbf{0}$ + 45 - 61657209, $\square$ miguel@itu.dk, www.miguelsicart.com 


\section{Introduction}

When researching about computer games and their value system, it is a usual method to analyze the behavior of their users, evaluating the results in order to understand what computer games are and how they affect their users (Anderson \& Dill: 2000). The problem is that these studies are trustworthy only when it comes to understanding how game users react to game testing. They say very little about what computer games are, and what is to be a player, because the answers to those questions seem to be given by default.

This paper argues for the understanding of what games are, what a player is, and which kind of ethical questions computer games pose from an ethical theory perspective. Following Philip Brey's applied ethics methodology (Brey:2000), this paper will first determine why computer games pose ethical problems. Those problems will be described using ethical conceptual terms, and finally they will be interpreted by ethical theory trying to reach a resolution on the ethical nature of computer games.

This paper intends to address two communities: philosophers and ethicists should be interested in the analysis of computer games as they pose ethical dilemmas in the intersection of arts, culture and technology. On the other hand, game designers might be interested not only in the argumentation that explains the ethics of games, but also because implementing ethical discourses in game design might lead to more mature, challenging products.

\section{What games are}

Chess, go, football, poker, Counter Strike: what do these objects have in common? They are all games, but they all are very different kinds of objects and experiences. They do present, though, some elements that make them definable as the same class of objects. Those elements, then, are what make certain objects be considered games: which are those? How can we define games?

Since 2001 (Aarseth:2001), it is possible to talk about computer game research as an academic field, related to a broader discipline with a relative short tradition; a discipline whose founding fathers are Johan Huizinga, Roger Caillois, and Brian Sutton-Smith, whose influence reaches the works of Espen Aarseth or Eric Zimmermann (Salen \& Zimmerman: 2003). The central research question for most of these theorist is: what are games. In this paper I will use the latest most comprehensive approach to the ontological nature of computer games: the work of J esper Juul.

According to Juul, "a game is a rule-based system with a variable and quantifiable outcome, where different outcomes are assigned different values, the player exerts effort in order to influence the outcome, the player feels attached to the outcome, and the consequences of the activity are optional and negotiable" (Juul: 2004, p. 30). And video games are "games played using computer power, where the computer upholds the rules of the game and the game is played using a video display" (ibid, p. 1). Juul has achieved a syncretism in the ontological level that allows game researchers to share concepts and approaches. In a certain sense, the ontological question about computer games needs to be grounded in a common language, and that is what Juul has provided.

For this paper's sake, the most interesting distinction in Juul's definition details the difference between a level of systemic rules, and the level of fictionality that most computer games create. This approach actually means that games can be analyzed as systems and as worlds, and as both, in the ways they interrelate. Both the virtual world and the rules are formal abstractions that seem not to take into account the existence of a player, or the phenomenology of playing. This dichotomy is crucial for the ethical understanding of a game, as it empowers the players as moral beings with the ability to judge their own experiences according to ethical values and cultural practices.

Summarizing, a game is a formal set of rules that project a fictional world that a player has to experience. A game is also the experience of play in a formalized rule set environment (Zimmerman \& Salen: 2003). Therefore, it might be possible to say that a game only exists when played, even though we can describe its rules. These rules, being the objective nature of the game, might be considered as a relevant part in the ethical construction of the experience, as the constraints and affordances that impose on the player might actually have embedded values (Winner: 1986, Norman: 2002) If we want to understand the ethics of computer games we need to be able to determine precisely how a computer game as a moral object and experience is constituted. To do so, I will apply Aristotle's distinction between potentia and actio. 


\section{Games in potentia, Games in actio}

I can take the rulebook of any game, say chess, and read it. Holding that book in my hands, I can say, this is chess. In a certain sense, I am not committing a fallacy. On the other hand, I am neglecting not only the whole history of chess, but also many things that are a part of the game, but that are not in that rule book: the physical presence or absence of the players, the sudden glimpse of a flaw in the opponent's strategies, ... A game is not only its rules, its material aspect, but also its experience the act of playing the game. A game is both its rules and the practical existence of those rules. To understand this duality, I will use a classic distinction of Aristotelian metaphysics: that of potentiality and actuality.

According to Aristotle's metaphysics, things present a potentiality, the capability of becoming into a different and more complete state, which would be the actuality of that thing. The classic example would be a boy being the potentiality of a man. More importantly, Aristotle argues that actuality is prior and has priority over actuality: before defining what a potentiality might be, we have to have known its actuality; and it is this actuality which is the reason why the potentiality is not only acquired, but developed.

In computer games, as in any other kind of games, this would mean that the rules of a game contain the potentiality of the game, but only when the game is played we can actually say something about the game as such. In a game like Tetris, the rule set (geometrical pieces fall down at an increasingly fast rhythm, the goal is to avoid filling the screen with these pieces) is the conditions for the game, that which the players have to accept in order to play. The rule set, in its own, contains the ways the game can be played, but only the presence of a player will activate those potentialities and make them become a game.

When game designers talk about their practice, they often say that their role is to predict player behavior, and plot their interaction with the system in ways that encourage the playability of the game. This means that the rules of the game are designed with a series of affordances and constraints, relative to the choices given to the players, which condition the experience of the game by its users. The potentiality of the game, therefore, is a designed formal system that predicts a certain experience. We can analyze the rules of a game as ethical objects - because they constitute the potentiality of a game, but we cannot say that it is the rule set of the game, or in a broader sense its design, that which sets the ethical values of the game.

When reading the criticism some games like Grand Theft Auto: San Andreas has received for its violent content, media and game critics seem to focus only on the analysis of the ethical affordances of the game as a possibility. Ultimately, a game is not the object we describe when we write about the rules and the fictional universe, but the experience constructed by the interaction of a user with that world. In a sense, Grand Theft Auto: San Andreas, only exists as a moral experience when played, while it certainly is a moral object of incomplete nature when only described.

Games from their design are moral objects, but we need to consider how they are experienced by players in order to fully understand the ethics of computer games. In the next chapter, I will make a short introduction to what is a player, and how she relates to the given, designed experience a game's actuality is.

\section{Being an Ethical Player}

Aristotle (1998) defined ethics as a practical science, as a practice of virtues oriented towards the achievement of a better life. To do so, human beings had to use their judgement to evaluate the situations in which they were immersed, and thus take choices according to the will of being a good human being. In Aristotle's terms, ethics is a praxis guided by the phonesis or judgment, of the human beings that have the desire to achieve virtue.

Applying Aristotle's virtue ethics to computer games introduces a certainly interesting set of conditionals: If a game is a set of unambiguous rules the player has to accept in order to achieve goals, it might be possible to say that a good player in Aristotelian sense is who obeys the rules and uses her judgment in order to achieve the goals given the appropriate circumstances. If this were true, the whole notion of sportsmanship would be rendered obsolete. But that does not happen. There is more to a game than just its rules, and therefore being a good player from an ethical perspective is more than just obeying uncritically the rules.

Computer games players are moral beings that evaluate their actions and the choices they make. There is a explicit use of what Aristotle would call phronesis in the acts of any computer game player: 
as long as the rules of the game and the fictional world are seen as a coherent entity where the choices contribute to the enjoyment of a valid ludic experience, the player accepts the "willing suspension of disbelief". But playing a game, the act of activating the potentiality of the rules and fictional world by engaging in pre-established play, is an act of judgment too. Fair players are not those who just want to win, but those who play in an ethical way.

Playing is an act of judgment of the rule systems and the fictional world the player is presented with. So far, I have defined a game as a system of rules that projects a fictional world that has to be experienced by a player in order to achieve its actuality. A player is then the ethical being that interacts with the rules and the fictional world, and whose choices are determined by the goals of the game, limited by the rules, and evaluated by a combination of the individual values, the players communities values, and the cultural, or in real life (IRL) values. The following chapter will prove with a game example that this is a valid way of approaching the ethics of computer games.

\section{The Honor of Players}

Azeroth is a world is devastated by a unending wars. The Alliance of followers of the light is in trouble when seeing the mighty powers of the Horde. Local struggles as well as huge battles are everyday's source for sorrow and glory in this world, for its four million inhabitants.

Azeroth is, needless to say, a virtual world. It is the World of Warcraft, the Massive Multiplayer Online Roleplaying game that at the moment of writing, September 2005, dominates the market of online gaming. And it is also the best example for the complexity of ethical discourses and attitude computer games actually present, thanks to the historical evolution of the so-called Honor System (http://forums-en.wow-

europe.com/thread.aspx?fn=wow-pvp$\underline{\text { en } \& t=24040 \& p=1 \& t m p=1 \text { - post24040) }}$.

When the game was launched in March 2005, it came as almost a surprise that the designers actually implemented a system for player vs. player combat (pvp henceforth) in certain servers. Traditionally, pvp gameplay was limited to certain spaces were, by common agreement, players could actually engage in combat that is much more satisfying than defeating a very limited A.I. The following success of the game only reassured the designers in their choices: players were happy with that design decision, which actually matched very well with the fantasy world created by the game.

The designers decided to take pvp one step further, and chose to implement an honor system, by which players could get points after killing other players; points that yielded lucrative in-game rewards. An honor system, worth is mentioning, that did not include dishonor. This fact, coupled with a very poor information provided by the designer team and the very nature of the Honor reward system, motivated the spawn of what the community considered unethical actions, corpse camping (that is, waiting for the other player's to resurrect to eliminate them again while they were weak) and ganking (attacking players who cannot defend themselves) being the most widespread. The quality of gameplay was lowered in the pvp servers, and the community soon expressed its polarized division in the game forums. Some liked the Honor system, but some disliked it to the extent that they abandoned playing in the pvp servers.

Currently, the situation has improved, as the designers have included special map instances focused exclusively on pvp combat, with rewards that are still honor based - but now honor is acquired faster and more effectively in these so called Battlegrounds.

Why is World of Warcraft a good example of how computer games' ethics are constructed? Because through time it is possible to see the different instances that create the overall values of the game. In the design of the game, both in the rules and in their implementation as a fictional world, we can see the designers initially affording certain kinds of gameplay, pvp, and leaving its constraining to the community. When playing this game, players constructed an implicit code of values that controlled the values of the game. Then the game designers decided to include Honor as an affordance hardwired in the rule system of the game, but they did not provide any constraint to the behaviors this system might encourage. The community largely reacted against this implementation, as they understood as highly unethical this new set of affordances, to the extreme of abandoning the pvp servers. Finally, designers came up with another affordance, the organized battlegrounds, that would satisfy those players who saw indiscriminate pvp as a threat to their gameplay, but that would also grant popularity among those players who actually enjoyed the honor system. 
In this example it is possible to see both how the game can be designed or implemented with certain affordances on the rules level that affect the ways players experience the game; but, most importantly, it also shows that players act as moral beings, that they reflect upon those values that are contained in the system of the game, and that they evaluate them keeping in perspective the values of the game world, of the player's community, and ultimately cultural values. The honor system proves that players are reflective moral beings that afford a series of values in the games they play, and evaluate their acts with what Aristotle would call phronesis. Players are morally accountable, just like computer games are. As a matter of fact, the game as being, the actuality of the game, is a moral object and experience because its two main elements, the player and the rule/fictional systems, are ethical entities responsible for the well being of the whole experience of playing a game.

\section{Conclusions}

Computer games pose new and interesting questions to ethical theory. As ethicists, we should take a step forward and try to understand why computer games are attributed these almost magical powers when it comes to their effects on the player's values. In this paper I have argued for a virtue ethics reading of computer games, one that takes into account the particular nature of computer games, but also that considers players as a key element in the overall construction of meaning of computer games.

There are, though, a whole set of issues I have not analyzed in this article, which provide interesting ethical dilemmas within computer games culture. For example, some MMOs do have an effect in reallife economy (Castronova: 2003), which brings forth interesting ethical questions concerning the relations between the gameworld and the real world, and how both interrelate. In this article I chose to provide a more general framework by which these questions could be approached, but I leave for further research any closer look to other ethical questions about computer games that, I would argue, could be analyzed using the virtue ethics framework I have here suggested.

I have argued that players are actually reflective, and responsible for the choices they take while playing games. Games are objects designed with affordances that suggest a certain experience that is evaluated by its players' moral sense. As an ethicist,
I would look at the game design, but also at the community practices and players' responses to the content of the game. Because it is players who ultimately give reason for games to exist, and without them, their morality is just a potentiality, but never just a game.

\section{References Literature}

Aarseth, Espen. Cybertext. Perspectives on Ergodic Literature. Baltimore: The John Hopkins University Press, 1997.

---. "Allegories of Space: The Question of Spatiality in Computer Games." Cybertext Yearbook 2000. Ed. Markku Eskelinen, and Raine Koskimaa. Jyväskylä: University of Jyväskylä, 2000.

---. "Computer Game Studies, Year One." Game Studies 1.1 (2001).

Anderson, Craig A. \& Karen E. Dill. "Video Games and Aggressive Thoughts, Feelings and Behavior in the Laboratory and in Life." Journal of Personality and Social Psychology 78.4 (2000): 77290.

Aristotle. Metaphysics. The Internet Classics Archive. http://classics.mit. edu/Aristotle/metaphysics. ht $\mathrm{ml}$.

---. Nicomachean Ethics. IV B.C. Trans. William Kaufman. Unabridged Dover. Mineola, NY: Dover, 1998.

Brey, Philip. "Method in Computer Ethics: Towards a Multi-Level Interdisciplinary Approach." Ethics and Information Technology 2:3.1-5 (2000).

Castronova, Edward, "On Virtual Economies", Game Studies 3.2 (2003)

Caillois, Roger. Man, Play and Games. 1958. Trans. Meyer Barash. Urbana and Chicago: University of Illinois Press, 2001.

Costikyan, Greg. "Games Don't Kill People -- Do They?" Salon.com June 2119991999.

Crawford, Chris. On Game Design. Indianapolis: New Riders, 2003.

Dreyfus, Hubert L. On the Internet. 2001. Thinking in Action. Ed. Simon and Richard Kearney Critchley. London and New York: Routledge, 2003. 2002, 2003.

Floridi, Luciano and J.W. Sanders. "Internet Ethics: The Constructionist Values of Homo Poieticus." The Impact of the Internet in Our Moral Lives. Ed. R. Cavalier. New York: SUNY, 2003.

Frasca, Gonzalo. "Videogames of the Oppressed: Critical Thinking, Education, Tolerance, and Other Trivial Issues. " First Person. New Media as Story, Performace, and Game. Ed. Noah and Pat 
Harrigan Wardrip-Fruin. London \& Cambridge: The MIT Press, 2003. 85 - 94.

Gibson, J.J. "The Theory of Affordances." Perceiving, Acting, and Knowing. Ed. R.E. Shaw \& J. Bransford. Hillsdale, NJ: Lawrence Erlbaum Associates, 1977.

Juul, Jesper. "The Game, the Player, the World: Looking for a Heart of Gameness." Level Up. Digital Games Research Proceedings. Ed. Marinka and Joost Raessens Copier. Utrecht: University of Utrecht, 2003. 30-45.

---. Half-Real: Video Games between Real Rules and Fictional Worlds. Copenhagen: IT University of Copenhagen, 2004.

Lessig, Lawrence. Code and Other Laws of Cyberspace. 1999. New York: Basic Books, 1999.

Norman, Donald. The Design of Everyday Things. Basic Books. New York: Perseus, 2002.

Stanislavski, Constantin. Building a Character. 1950. Trans. Elizabeth Reynolds Hapgood. Methuen Drama. London: Methuen, 2003.

Sutton-Smith, Brian. The Ambiguity of Play. Cambridge: Harvard University Press, 2001.

Turing, Alan. "Computing Machinery and Intelligence." Mind 59 (1950): 433-60.

Winner, L. "Do Artifacts Have Politics?" The Whale and the Reactor: A Search for Limits in an Age of High Technology. Chicago: University of Chicago Press, 1986. 13-39.

Zimmerman, Eric and Katie Salen. Rules of Play Game Design Fundamentals. Cambridge: The MIT Press, 2003.

\section{References Games}

Blizzard, World of Warcraft, Blizzard 2005

Pazhitnov, Alexey: Tetris. Spectrum Holobyte, 1985.

Rockstart North, Grand Theft Auto: San Andreas, Take Two Interactive Software 2004

The Counter-Strike Team, Counter-Strike. The Counter-Strike Team, 2000. 